\title{
Impact of Shoulder Subluxation on Peripheral Nerve Conduction and Function of Hemiplegic Upper Extremity in Stroke Patients: A Retrospective, Matched-Pair Study
}

\section{Xiangzhe Li}

Nanjing Medical University https://orcid.org/0000-0003-0979-0160

Zhiwei Yang

Nanjing Medical University

Sheng Wang

Nanjing Medical University

Panpan Xu

Nanjing Medical University

Tianqi Wei

Nanjing Medical University

Xiaomeng Zhao

Nanjing Medical University

Xifeng Li

Nanjing Medical University

Yanmei Zhang

Nanjing Medical University

\section{Ying Li}

Nanjing Medical University

$\mathrm{Na}$ Mei

Nanjing Medical University

Qinfeng Wu ( $\nabla$ wuqinfeng0911@163.com )

\section{Research article}

Keywords: Stroke, Shoulder subluxation, Peripheral nerve conduction, Upper extremity function, Electromyography

Posted Date: July 22nd, 2020 
License: (c) (i) This work is licensed under a Creative Commons Attribution 4.0 International License. Read Full License

Version of Record: A version of this preprint was published at Neurological Research on January 5th, 2021. See the published version at https://doi.org/10.1080/01616412.2020.1870360. 


\section{Abstract}

Background: After stroke, the peripheral nerves of the hemiplegic upper extremity (HUE) could exist impairments which seriously delay the function recovery of the HUE. However, the impacts of shoulder subluxation (SS) on the HUE electromyography characteristics in post-stroke are rarely reported. Therefore, this study was to investigate the impact of SS on peripheral nerve conduction and function of the HUE in post-stroke patients.

Methods: A retrospective, matched-pair study was conducted. 30 post-stroke in-patients (15 patients for each group) were selected and their peripheral nerves of bilateral upper limbs were used to be underdone by the electroneurographic examination. The characteristics of patients, such as age and type of stroke, were recorded and paired. The electroneurographic parameters of upper limb motor/sensory nerves contained: the compound muscle action potential (CMAP) amplitude and latency of suprascapular, axillary, musculocutaneous, radial, median and ulnar nerves; the motor conduction velocity/ the sensory nerve action potential (SNAP) amplitude and latency of median, ulnar and radial nerves. The Brunnstrom stage scale was used to evaluate the motor function of the HUE.

Results: The CMAP amplitude of each nerve in the HUE of both groups was lower than that in the healthy side $(P<0.05)$. CMAP amplitude of peripheral nerves (except ulnar) in the HUE of SS group was decreased $(P<0.05)$. The CMAP latency of the suprascapular, axillary and musculocutaneous nerves was longer than that of the healthy side in the SS group $(P<0.05)$. The axillary nerve CMAP latency in the SS group was prolonged more $(P<0.05)$. The motor conduction velocity of the median nerve on the HUE in the SS group was lower than that of the HUE in the N-SS group $(P<0.05)$. The SNAP amplitudes of the nerves in the HUE in both groups were lower than those in the healthy side $(P<0.05)$. The Brunnstrom stage of HUE in the SS group was lower $(P<0.05)$.

Conclusions: Stroke may lead to extensive damage of the HUE nerves, and SS may aggravate the damage of these nerves, delaying the recovery of upper limb function.

\section{Background}

Shoulder subluxation (SS) or glenohumeral subluxation is one of the common complications in poststroke setting, with an incidence of approximately $17 \%-81 \%{ }^{[1,2]}$. After a stroke, the hemiplegic upper extremity (HUE) could be affected by muscle weakness, gravity traction, incorrect posture transfer, or peripheral nerve/rotator cuff injury, so the humeral head partially detaches from the glenoid, which leads to the $S S^{[1,3]}$. After a SS, the shoulder joint capsule, the surrounding tendons and the brachial plexus nerves could be pulled by the HUE ${ }^{[4,5]}$. Then, the degree of SS and upper limb dysfunction could be further aggravated ${ }^{[1,3]}$.

Electrodiagnosis and ultrasound medicine studies show that, in post-stroke patients, the peripheral nerves of the HUE could exist different degrees of impairment which seriously delays the function recovery of the 
HUE ${ }^{[6-8]}$. However, the impacts of SS on the HUE electroneurographic characteristics in post-stroke are rarely reported.

In the 1980s, Chino et al. ${ }^{[5]}$ only observed the variations of peripheral nerve conduction (suprascapular nerve, axillary nerve, musculocutaneous nerve and radial nerve) in the HUE among post-stroke patients with an occurrence of SS, rather than comparison with healthy upper limb and the HUE without SS. Tsur et al. ${ }^{[9]}$ investigated the difference of the axillary nerve between the HUE after SS and its healthy upper limb, other nerves were not analyzed. So far, no study has comprehensively assessed the degree of peripheral nerve injury in HUE after SS.

Therefore, it is necessary to further analyze the variations of peripheral nerve conduction and function in HUE after SS. The main purpose of this study was to investigate the impact of SS on peripheral nerve conduction and function of the HUE in stroke patients through the comparison of peripheral nerve conduction parameters between the HUE with SS and without SS.

\section{Methods}

\section{Study design}

This was a retrospective, matched-pair single-center study based on data collected from the Department of Rehabilitation Medicine, the Affiliated Suzhou Science and Technology town Hospital of Nanjing Medical University.

\section{Participants}

Post-stroke patients were selected who were hospitalized from June 2018 to May 2020 and their peripheral nerves of bilateral upper limbs had been undergone by the electroneurographic examination. The characteristics of patients, such as age, gender, type of stroke, hemiplegic side, handedness, height, weight and disease duration, were recorded and paired in terms of retrospective, matched-pair study design ${ }^{[10]}$.

Inclusion criteria: 1) age 18-75 years old; 2) the first onset of unilateral basal ganglia hemorrhage/ischemia stroke confirmed by MRI/CT and with a course of more than 1 month; 3 ) be able to accept electroneurographic examination of the bilateral upper limbs peripheral nerves; 4 ) the existence of the SS determined by physical examinations or imaging tests (Fig. 1). Exclusion criteria: 1) medical history of upper limb peripheral nerve injury or upper limb surgery/trauma in pre-stroke; 2) diagnosis of the complex regional pain syndrome ${ }^{[11]}$; 3 ) diagnosis of upper limb peripheral nerve entrapment syndrome ${ }^{[12]}$; 4) diagnosis of diabetes ${ }^{[13]}$.

This study was approved by the Medical Ethics Committee of the Affiliated Suzhou Science and Loading [MathJax]/jax/output/CommonHTML/jax.js al University (approval number: IRB2019062). 
Evaluation of nerve conduction ${ }^{[14]}$

The Keypoint electromyograph/evoked potential device (Keypoint G4, Dantec medical, Denmark) was operated by a five years qualified physician to administer evaluation of nerve conduction on all participants.

\section{Evaluation of upper limb motor nerve conduction}

Patient was in a supine position. The saddle-shape electrode was used as stimulating electrode, the superficial electrode was used as recording and reference electrode, and the ground electrode was placed between the stimulating electrode and the recording electrode. The placement of each electrode was outlined in Table 1.

Table 1

Evaluation of upper limb motor nerve conduction

\begin{tabular}{|c|c|c|c|c|c|}
\hline Peripheral nerves & $\begin{array}{l}\text { The location } \\
\text { of the } \\
\text { recording } \\
\text { electrode }\end{array}$ & $\begin{array}{l}\text { The location } \\
\text { of the } \\
\text { reference } \\
\text { electrode }\end{array}$ & $\begin{array}{l}\text { The } \\
\text { location of } \\
\text { the } \\
\text { stimulating } \\
\text { electrode }\end{array}$ & $\begin{array}{l}\text { Latency } \\
\text { and CMAP } \\
\text { amplitude }\end{array}$ & $\begin{array}{l}\text { Motor } \\
\text { conduction } \\
\text { velocity }\end{array}$ \\
\hline Median & $\begin{array}{l}\text { Abductor } \\
\text { pollicis brevis }\end{array}$ & \multirow{6}{*}{$\begin{array}{l}\text { on the tendon } \\
\text { for reference } \\
\text { using the } \\
\text { belly-tendon } \\
\text { method }\end{array}$} & $\begin{array}{l}\text { Wrist and } \\
\text { elbow }\end{array}$ & \multirow{2}{*}{$\begin{array}{l}\text { recorded } \\
\text { by wrist } \\
\text { stimulation }\end{array}$} & \multirow{3}{*}{$\begin{array}{l}\text { the distance } \\
\text { between two } \\
\text { points of } \\
\text { stimulation } \\
\text { divided by the } \\
\text { conduction } \\
\text { time. }\end{array}$} \\
\hline Ulnar & $\begin{array}{l}\text { abductor } \\
\text { digiti minimi }\end{array}$ & & $\begin{array}{l}\text { Wrist and } \\
\text { Ulnar nerve } \\
\text { groove }\end{array}$ & & \\
\hline Radial & $\begin{array}{l}\text { Extensor } \\
\text { digitorum } \\
\text { communis }\end{array}$ & & $\begin{array}{l}\text { Elbow and } \\
\text { Radial } \\
\text { nerve } \\
\text { groove }\end{array}$ & $\begin{array}{l}\text { recorded } \\
\text { by elbow } \\
\text { stimulation }\end{array}$ & \\
\hline Musculocutaneous & biceps brachii & & \multirow{3}{*}{$\begin{array}{l}\text { Brachial } \\
\text { plexus } \\
\text { (Erb's) }\end{array}$} & \multirow{3}{*}{$\begin{array}{l}\text { recorded } \\
\text { by Erb's } \\
\text { point } \\
\text { stimulation }\end{array}$} & - \\
\hline Axillary & $\begin{array}{l}\text { anterior } \\
\text { deltoid bundle }\end{array}$ & & & & - \\
\hline Suprascapular & supraspinatus & & & & - \\
\hline
\end{tabular}

When motor nerve conduction was assessed, the intensity of electrical stimulation gradually increased until the compound muscle action potential (CMAP) amplitude reached its maximum, and the amplitude was the distance between the baseline and the negative peak.

\section{Evaluation Of Upper Limb Sensory Nerve Conduction}


The saddle-shape electrode was used as stimulating electrode, the ring-shape electrode or superficial electrode was used as recording and reference electrode. The sensory nerve action potential (SNAP)/conduction velocity of the median nerve, ulnar nerve and radial nerve was recorded. The placement of each electrode was outlined in Table 2.

Table 2

Evaluation of upper limb sensory nerve conduction

\begin{tabular}{|c|c|c|c|c|c|}
\hline $\begin{array}{l}\text { Peripheral } \\
\text { nerves }\end{array}$ & $\begin{array}{l}\text { The location of } \\
\text { the recording } \\
\text { electrode }\end{array}$ & $\begin{array}{l}\text { The location of the } \\
\text { reference electrode }\end{array}$ & $\begin{array}{l}\text { The } \\
\text { location of } \\
\text { the } \\
\text { stimulating } \\
\text { electrode }\end{array}$ & $\begin{array}{l}\text { SNAP } \\
\text { amplitude }\end{array}$ & $\begin{array}{l}\text { Sensory } \\
\text { conduction } \\
\text { velocity }\end{array}$ \\
\hline Median & $\begin{array}{l}\text { Between the } \\
\text { thumb and } \\
\text { forefinger }\end{array}$ & $\begin{array}{l}\text { Metacarpophalangeal } \\
\text { joint of the back of } \\
\text { the forefinger }\end{array}$ & \multirow{3}{*}{$\begin{array}{l}\text { stimulated } \\
\text { at } 14 \mathrm{~cm} \\
\text { from the } \\
\text { recording } \\
\text { electrode }\end{array}$} & \multirow{3}{*}{$\begin{array}{l}\text { the } \\
\text { distance } \\
\text { from } \\
\text { baseline } \\
\text { to } \\
\text { negative } \\
\text { peak }\end{array}$} & \multirow{3}{*}{$\begin{array}{l}\text { the distance } \\
\text { between } \\
\text { stimulating } \\
\text { electrode and } \\
\text { recording } \\
\text { electrode } \\
\text { divided by } \\
\text { latency. }\end{array}$} \\
\hline Ulnar & $\begin{array}{l}\text { Proximal } \\
\text { interphalangeal } \\
\text { joint of } \\
\text { forefinger }\end{array}$ & $\begin{array}{l}\text { Distal interphalangeal } \\
\text { joint }\end{array}$ & & & \\
\hline Radial & $\begin{array}{l}\text { Proximal } \\
\text { interphalangeal } \\
\text { joint of little } \\
\text { finger }\end{array}$ & $\begin{array}{l}\text { Distal interphalangeal } \\
\text { joint }\end{array}$ & & & \\
\hline
\end{tabular}

When sensory nerve conduction was assessed, the stimulus intensity gradually increased until the baseline of the waveform was stable and the maximum amplitude arrived, and the waveform was superimposed 30 times. The SNAP amplitude is the distance from baseline to negative peak, and conduction velocity is the distance between stimulating electrode and recording electrode divided by latency.

\section{The variation rate of nerve conduction parameters on HUE}

The nerve conduction parameters (CMAP amplitude, SNAP amplitude, latency and conduction velocity) on the unaffected side was used as a reference to evaluate the variation rate of the nerve conduction parameters on the HUE. The formula for calculating the variation rate is as follows:

$$
\text { Variationrate }=\left(\frac{\text { NerveconductionparameteronHUE }}{\text { Nerveconductionparameteronunaffectedside }}-1\right) \times 100 \%
$$

The positive value of change rate represents the percentage of increase compared with the healthy side, and the negative value represents the percentage of decrease compared with the healthy side. 
The Brunnstrom stage scale was used to evaluate the motor function of upper limb and hand on the hemiplegic side ${ }^{[15]}$.

\section{Statistical analysis}

In post-stroke, the parameters of the HUE nerve conduction in patients with SS and without SS were compared. Sample size was calculated using G*Power (3.1.7.). According to the design of matched-pair study, if the effect size $d=0.5$, alpha error $=0.05$, and power $(1$-beta $)=0.8,27$ patients were required. Hence, a total of 28 patients, 14 for each group should be sufficient for this study.

Statistical analysis was performed using SPSS 22.0 software, and measurement data were expressed as $\pm S$. Age, clinical course, height, weight, motor and sensory nerve conduction parameters (CMAP amplitude, SNAP amplitude, latency, sensory and motor nerve conduction velocity, and the variation rate. etc) between two groups were analyzed by paired t-test. The Brunnstrom stage between the two groups was compared using the Wilcoxon signed rank sum test. $\mathrm{P}<0.05$ was set as a statistically significant difference.

\section{Results}

\section{Demographic characteristics}

A total of 30 patients were selected and 15 patients with SS were allocated to the SS group, other 15 without SS were allocated to Non-shoulder subluxation group (N-SS group). There were no significant differences in age, height, weight and clinical course between the SS group and the N-SS group $(P>0.05$, Table 3). 
Table 3

Clinical characteristics of patients with or without SS

\begin{tabular}{|c|c|c|c|c|}
\hline \multicolumn{2}{|l|}{ Characteristic } & \multirow{2}{*}{$\begin{array}{l}S S(n=15) \\
10\end{array}$} & \multirow{2}{*}{$\begin{array}{l}\text { N-SS(n=15) } \\
10\end{array}$} & \multirow{2}{*}{ P value } \\
\hline Gender & Male & & & \\
\hline & Female & 5 & 5 & \\
\hline \multicolumn{2}{|c|}{ Age(mean $\pm S D$, years $)$} & $57.53 \pm 11.92$ & $57.33 \pm 12.61$ & 0.842 \\
\hline \multirow[t]{2}{*}{ Stroke type } & hemorrhagic & 6 & 6 & \multirow[t]{2}{*}{-} \\
\hline & ischemic & 9 & 9 & \\
\hline \multirow[t]{2}{*}{ Hemiplegia Side } & Lift & 7 & 7 & \multirow[t]{2}{*}{-} \\
\hline & Right & 8 & 8 & \\
\hline \multirow[t]{2}{*}{ Handedness } & Lift & 1 & 1 & \multirow[t]{2}{*}{-} \\
\hline & Right & 14 & 14 & \\
\hline \multicolumn{2}{|c|}{ Height(mean \pm SD, cm) } & $165.60 \pm 7.80$ & $165.53 \pm 7.08$ & 0.955 \\
\hline \multicolumn{2}{|c|}{ Weight(mean \pm SD, Kg) } & $67.93 \pm 8.85$ & $68.80 \pm 6.17$ & 0.605 \\
\hline \multicolumn{2}{|c|}{ Disease duration(mean $\pm \mathrm{SD}$, months) } & $3.07 \pm 1.53$ & $3.47 \pm 1.85$ & 0.348 \\
\hline
\end{tabular}

\section{Cmap Amplitude}

No significant difference in the CMAP amplitude of each nerve on the healthy upper limb between the two groups was evident $(P>0.05)$. The CMAP amplitude of each nerve in the affected upper limb of both groups was significantly lower than that in the healthy side $(P<0.05)$. Compared with the affected side of the N-SS group, CMAP amplitude of suprascapular nerve, axillary nerve, musculocutaneous nerve, radial nerve and median nerve in the HUE of the SS group were significantly decreased $(P<0.05)$. No significant difference in the CMAP amplitude of ulnar nerve on the HUE between the two groups was found $(P>$ 0.05). The CMAP amplitude variation rate of the suprascapular nerve, the axillary nerve, the musculocutaneous nerve and the median nerve in the HUE of the SS group significantly decreased more than that of in the N-SS group $(P<0.05)$. There was no significant difference in the CMAP amplitude variation rate between the SS group and the N-SS group in the radial nerve and the ulnar nerve of the HUE $(P>0.05$, Table 4). 
Table 4

The CMAP amplitude $(\mathrm{mV})$ of peripheral nerves on upper limb in patients with or without SS

\begin{tabular}{|c|c|c|c|c|c|}
\hline Nerves & $\begin{array}{l}\text { Less affected } \\
(n=15)\end{array}$ & $\begin{array}{l}\text { Affected } \\
(n=15)\end{array}$ & $\begin{array}{l}\text { variation rate } \\
(\%)\end{array}$ & t value & $P$ value \\
\hline \multicolumn{6}{|c|}{ Suprascapular } \\
\hline SS & $5.78 \pm 2.33$ & $3.66 \pm 1.72^{\square}$ & $-37.43 \pm 18.02^{\square}$ & 6.270 & 0.000 \\
\hline N-SS & $6.39 \pm 1.90$ & $5.09 \pm 1.29$ & $-18.36 \pm 11.49$ & 5.033 & 0.000 \\
\hline \multicolumn{6}{|l|}{ Axillary } \\
\hline SS & $10.63 \pm 1.75$ & $5.24 \pm 1.95^{\square}$ & $-50.46 \pm 18.81^{\square}$ & 9.957 & 0.000 \\
\hline $\mathrm{N}-\mathrm{SS}$ & $11.31 \pm 2.02$ & $8.48 \pm 2.40$ & $-25.85 \pm 13.13$ & 8.735 & 0.000 \\
\hline \multicolumn{6}{|c|}{ Musculocutaneous } \\
\hline SS & $9.47 \pm 1.77$ & $5.25 \pm 1.58^{\square}$ & $-43.95 \pm 15.45^{\square}$ & 8.116 & 0.000 \\
\hline $\mathrm{N}-\mathrm{SS}$ & $10.29 \pm 2.26$ & $7.99 \pm 1.79$ & $-20.82 \pm 17.72$ & 4.229 & 0.001 \\
\hline \multicolumn{6}{|l|}{ Radial } \\
\hline SS & $6.33 \pm 1.20$ & $4.71 \pm 1.31^{\square}$ & $-24.85 \pm 19.95$ & 4.846 & 0.000 \\
\hline N-SS & $7.19 \pm 1.30$ & $5.99 \pm 1.17$ & $-14.41 \pm 20.21$ & 2.600 & 0.021 \\
\hline \multicolumn{6}{|l|}{ Median } \\
\hline SS & $7.66 \pm 1.21$ & $5.34 \pm 1.30^{\square}$ & $-29.11 \pm 19.03^{\square}$ & 5.700 & 0.000 \\
\hline N-SS & $8.00 \pm 0.86$ & $6.95 \pm 1.16$ & $-12.35 \pm 16.03$ & 2.942 & 0.011 \\
\hline \multicolumn{6}{|l|}{ Ulnar } \\
\hline SS & $9.19 \pm 1.08$ & $7.60 \pm 1.55$ & $-17.30 \pm 13.08$ & 4.889 & 0.000 \\
\hline N-SS & $9.62 \pm 1.29$ & $8.71 \pm 1.67$ & $-9.43 \pm 11.95$ & 3.103 & 0.008 \\
\hline
\end{tabular}

\section{Cmap Latency}

No significant difference in the healthy upper limb CMAP latency between the two groups was evident ( $P$ $>0.05$ ). In the SS group, the CMAP latency of the suprascapular, the axillary and the musculocutaneous nerves in the HUE was significantly longer than that of the on the healthy side $(P<0.05)$, while the CMAP latencv of the radial nerve median nerve and ulnar nerve was not significantly different from that of on Loading [MathJax]/jax/output/CommonHTML/jax.js 
the healthy side $(P>0.05)$. In the N-SS group, there was no significant difference in corresponding nerves CMAP latency between the HUE and the healthy upper limb $(P>0.05)$. Compared with the N-SS group, the axillary nerve CMAP latency in the SS group was significantly prolonged more $(P<0.05)$, and there was no significant difference in CMAP latency between the two groups in the remaining nerves of the HUE ( $P$ $>0.05$ ). In the SS group, the variation rate of CMAP latency of the axillary and the suprascapular nerves on the HUE was significantly greater than that of in the N-SS group $(P<0.05)$, and the difference of CMAP amplitude variation rate between the two groups on the remaining nerves of the HUE was not statistically significant $(P>0.05$, Table 5$)$.

Table 5

The CMAP latency (msecs) of peripheral nerves on upper limb in patients with or without SS

$\begin{array}{llllll}\text { Nerves } & \text { Less affected } & \text { Affected } & \text { variation rate } & \text { t value } & \text { P value } \\ & (n=15) & (n=15) & (\%) & & \end{array}$

\section{Suprascapular}

$\begin{array}{llllll}\text { SS } & 2.73 \pm 0.86 & 3.14 \pm 0.91 & 15.73 \pm 15.64^{\square} & -0.460 & 0.001 \\ \text { N-SS } & 2.92 \pm 0.64 & 2.96 \pm 0.69 & 1.54 \pm 4.48 & -1.597 & 0.133\end{array}$

Axillary

$\begin{array}{llllll}\text { SS } & 4.13 \pm 0.35 & 4.95 \pm 0.53^{\square} & 20.19 \pm 13.47^{\square} & -6.108 & 0.000\end{array}$

$\begin{array}{llllll}\text { N-SS } & 4.20 \pm 0.42 & 4.28 \pm 0.46 & 2.12 \pm 5.86 & -1.343 & 0.201\end{array}$

\section{Musculocutaneous}

$\begin{array}{llllrl}\text { SS } & 4.36 \pm 0.44 & 4.53 \pm 0.43 & 3.98 \pm 6.71 & -2.366 & 0.033 \\ \text { N-SS } & 4.30 \pm 0.40 & 4.38 \pm 0.25 & 2.32 \pm 5.06 & -1.475 & 0.162\end{array}$

\section{Radial}

$\begin{array}{llllll}\text { SS } & 3.95 \pm 0.43 & 4.14 \pm 0.58 & 5.22 \pm 13.67 & -1.471 & 0.163 \\ \text { N-SS } & 3.93 \pm 0.33 & 4.08 \pm 0.33 & 4.08 \pm 7.86 & -1.982 & 0.067\end{array}$

\section{Median}

$\begin{array}{llllll}\text { SS } & 3.47 \pm 0.38 & 3.58 \pm 0.41 & 4.12 \pm 13.46 & -0.948 & 0.359 \\ \text { N-SS } & 3.46 \pm 0.35 & 3.48 \pm 0.28 & 1.03 \pm 7.10 & -0.374 & 0.714\end{array}$

\section{Ulnar}

$\begin{array}{llllll}\text { SS } & 2.40 \pm 0.27 & 2.47 \pm 0.40 & 2.85 \pm 10.97 & -0.999 & 0.335 \\ \text { N-SS } & 2.27 \pm 0.14 & 2.28 \pm 0.18 & 0.48 \pm 5.19 & -0.386 & 0.705\end{array}$

Values are mean \pm SD. CMAP: compound muscle action potential; SS: Shoulder subluxation; N-SS:

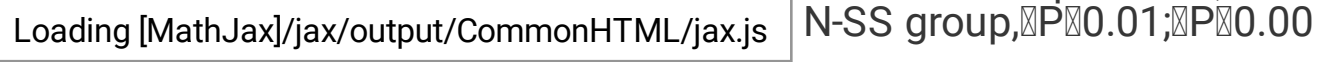




\section{Motor Nerve Conduction Velocity}

There was no significant difference in motor nerve conduction velocity on the healthy upper limb between the two groups $(P>0.05)$. The motor conduction velocity of the median nerve on the HUE in the SS group was significantly lower than that of the HUE in the N-SS group $(P<0.05)$, also, there was no significant difference on the conduction velocity of the radial nerve and the median nerve in the HUE between the two groups $(P>0.05)$. Besides, there was no significant difference in the variation rate of motor conduction velocity of radial, median and ulnar nerves in the HUE between the two groups $(P>0.05$, Table 6).

Table 6

The motor conduction velocity $(\mathrm{m} / \mathrm{sec})$ of peripheral nerves on upper limb in patients with or without SS

\begin{tabular}{|llllll|}
\hline Nerves & $\begin{array}{l}\text { Less affected } \\
(\mathbf{n}=\mathbf{1 5})\end{array}$ & $\begin{array}{l}\text { Affected } \\
(\mathbf{n}=\mathbf{1 5})\end{array}$ & $\begin{array}{l}\text { variation rate } \\
(\%)\end{array}$ & t value & P value \\
\hline Radial & & & & & \\
\hline SS & SS & $54.67 \pm 2.88$ & $-2.08 \pm 5.66$ & 1.789 & 0.095 \\
\hline N-SS & $57.27 \pm 2.17$ & $56.77 \pm 2.39$ & $-0.79 \pm 4.28$ & 0.778 & 0.450 \\
\hline Median & & & & & \\
\hline SS & SS & $52.79 \pm 2.83^{\square}$ & $-4.21 \pm 8.38$ & 2.059 & 0.059 \\
\hline N-SS & N-SS & $54.45 \pm 1.72$ & $-1.74 \pm 3.98$ & 1.787 & 0.096 \\
\hline Ulnar & & & & & \\
\hline SS & SS & $56.57 \pm 2.13$ & $-4.16 \pm 8.57$ & 2.037 & 0.061 \\
\hline N-SS & N-SS & $58.61 \pm 3.02$ & $-0.10 \pm 5.73$ & 0.151 & 0.882 \\
\hline
\end{tabular}

Values are mean \pm SD. SS: Shoulder subluxation; N-SS: Non-shoulder subluxation. Compared with N-

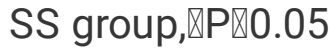

\section{Snap Amplitude And Sensory Conduction Velocity}

There was no significant difference in SNAP amplitude of radial, median and ulnar nerves on the healthy upper limb between the two groups $(P>0.05)$. The SNAP amplitudes of the nerves in the HUE in both groups were significantly lower than that in the healthy side $(P<0.05)$. There was no significant difference in SNAP amplitude and SNAP amplitude variation rate of the HUE between the two groups $(P>$ 0.05 , Table 7). 
Table 7

The SNAP amplitude $(\mu \mathrm{V})$ of peripheral nerves on upper limb in patients with or without SS

\begin{tabular}{|llllll|}
\hline Nerves & $\begin{array}{l}\text { Less affected } \\
(\mathbf{n = 1 5})\end{array}$ & $\begin{array}{l}\text { Affected } \\
(\mathbf{n}=\mathbf{1 5})\end{array}$ & $\begin{array}{l}\text { variation rate } \\
\mathbf{( \% )}\end{array}$ & t value & P value \\
\hline Radial & & & & \\
\hline SS & $12.97 \pm 4.12$ & $10.68 \pm 3.39$ & $-16.72 \pm 14.02$ & 3.966 & 0.001 \\
\hline N-SS & $13.85 \pm 3.91$ & $11.65 \pm 4.34$ & $-18.72 \pm 17.69$ & 5.668 & 0.000 \\
\hline Median & & & & & \\
\hline SS & $31.96 \pm 10.06$ & $22.60 \pm 11.83$ & $-30.62 \pm 30.22$ & 3.842 & 0.002 \\
\hline N-SS & $32.25 \pm 9.81$ & $27.54 \pm 11.00$ & $-17.42 \pm 17.11$ & 4.287 & 0.001 \\
\hline Ulnar & & & & & \\
\hline SS & $18.76 \pm 7.67$ & $14.81 \pm 8.36$ & $-22.05 \pm 23.00$ & 3.820 & 0.002 \\
\hline N-SS & $20.45 \pm 5.48$ & $17.93 \pm 4.76$ & $-10.62 \pm 19.31$ & 2.223 & 0.043 \\
\hline $\begin{array}{l}\text { Values are mean } \pm \text { SD. SNAP: sensory nerve action potential; SS: Shoulder subluxation; N-SS: Non- } \\
\text { shoulder subluxation. }\end{array}$ & & & & \\
\hline
\end{tabular}

\section{Sensory Nerve Conduction Velocity}

There was no significant difference in sensory conduction velocity of radial, median and ulnar nerves on the healthy upper limb between the two groups $(P>0.05)$. There was no significant difference in sensory conduction velocity of the HUE and the healthy side of the same group in the two groups $(P>0.05)$. There was no significant difference in SNAP velocity and SNAP velocity variation rates of radial, median and ulnar nerves in the HUE between the two groups $(P>0.05$, Table 8$)$. 
Table 8

The sensory conduction velocity $(\mathrm{m} / \mathrm{sec})$ of peripheral nerves on upper limb in patients with or without SS

\begin{tabular}{|llllll|}
\hline nerves & $\begin{array}{l}\text { Less affected } \\
(\mathbf{n = 1 5})\end{array}$ & $\begin{array}{l}\text { Affected } \\
(\mathbf{n}=\mathbf{1 5})\end{array}$ & $\begin{array}{l}\text { variation rate } \\
(\%)\end{array}$ & t value & P value \\
\hline Radial & & & & & \\
\hline SS & $53.48 \pm 3.67$ & $51.77 \pm 3.52$ & $-3.12 \pm 4.30$ & 2.765 & 0.015 \\
\hline N-SS & $54.55 \pm 3.25$ & $53.71 \pm 2.85$ & $-1.47 \pm 2.92$ & 2.010 & 0.064 \\
\hline Median & & & & & \\
\hline SS & $56.19 \pm 4.73$ & $52.95 \pm 6.32$ & $-5.66 \pm 9.67$ & 2.367 & 0.033 \\
\hline N-SS & $57.13 \pm 4.71$ & $55.10 \pm 6.11$ & $-3.60 \pm 6.64$ & 2.051 & 0.059 \\
\hline Ulnar & & & & & \\
\hline SS & $54.23 \pm 4.29$ & $52.05 \pm 4.04$ & $-3.69 \pm 8.20$ & 1.906 & 0.077 \\
\hline N-SS & $54.05 \pm 3.87$ & $52.53 \pm 4.09$ & $-2.71 \pm 5.79$ & 1.828 & 0.089 \\
\hline Values are mean \pm SD. SS: Shoulder subluxation; N-SS: Non-shoulder subluxation. \\
\hline
\end{tabular}

\section{Brunnstrom Stage}

Compared with the N-SS group, the Brunnstrom stage of hemiplegic upper limbs and hands in the SS group was lower, and the difference was statistically significant $(P<0.05$, Table 9,10$)$.

Table 9

The Brunnstrom stage on affected upper limb of patients with or without SS

\begin{tabular}{|c|c|c|c|c|c|c|c|c|}
\hline \multirow[t]{2}{*}{ Groups } & \multicolumn{6}{|c|}{ The Brunnstrom stage of upper limb } & \multirow[t]{2}{*}{$Z$ value } & \multirow[t]{2}{*}{$P$ value } \\
\hline & I & प & प & प & प & प & & \\
\hline$S S(n=15)$ & 4 & 7 & 4 & 0 & 0 & 0 & -2.739 & 0.006 \\
\hline$N-S S(n=15)$ & 2 & 3 & 6 & 3 & 1 & 0 & & \\
\hline
\end{tabular}


Table 10

The Brunnstrom stage on affected hand of patients with or without SS

\begin{tabular}{|c|c|c|c|c|c|c|c|c|}
\hline \multirow[t]{2}{*}{ Groups } & \multicolumn{6}{|c|}{ The Brunnstrom stage of hand } & \multirow[t]{2}{*}{$Z$ value } & \multirow[t]{2}{*}{$P$ value } \\
\hline & I & $\square$ & $\square$ & $\square$ & $\square$ & प & & \\
\hline$S S(n=15)$ & 8 & 3 & 3 & 1 & 0 & 0 & \multirow[t]{2}{*}{-2.153} & \multirow[t]{2}{*}{0.031} \\
\hline$N-S S(n=15)$ & 2 & 5 & 7 & 1 & 0 & 0 & & \\
\hline
\end{tabular}

\section{Discussion}

This is a retrospective, matched-pair study and it conducts the comparison in upper limb nerve conduction/motor function of the HUE between post-stroke patients with SS and without SS. The results showed that: 1) there was extensive damage to the peripheral nerves of the HUE after stroke; 2) the occurrence of SS could lead to greater damage to the suprascapular, axillary, musculocutaneous, radial and median motor nerves of the HUE than patients without SS; 3 ) the occurrence of SS could lead to greater prolongation of the latency of the axillary and suprascapular nerves on the HUE than patients without SS; 4) hemiplegic upper limb and hand function recovery may be worse in stroke patients with SS than in those without SS.

Stroke can lead to extensive damage of peripheral nerves (demyelination changes, axonal damage, etc.) in the HUE, which may affect the functional recovery of the HUE ${ }^{[6,7,16-18]}$. In the early stage of stroke, due to the weak deltoid and supraspinatus on the HUE, combined with the effect of gravity, the humeral head could not be effectively fixed into the glenoid, which may lead to the occurrence of $S S^{[1,19]}$.

The results of this study suggest that SS may lead to more severe peripheral nerve damage in the upper extremity after stroke. Previous studies have confirmed that ${ }^{[20,21]}$, traumatic shoulder dislocation often leads to traction damage of upper limb nerves, especially axillary nerves. Anatomically, the axillary, musculocutaneous, radial and median nerves all travel/pass near the humerus ${ }^{[22]}$. Therefore, combined with the results of the current study, the humeral head downward displacement after SS may cause traction damage of the above nerves. Compared with other upper limb nerves, the ulnar nerve has the lowest degree of damage which may be due to the farther anatomical relationship between the ulnar nerve and humerus ${ }^{[22]}$. However, the specific mechanism of upper limb nerve damage caused by SS after stroke needs further study.

The suprascapular nerve originates from the brachial plexus and it crosses the suprascapular notch and the transverse scapular ligament to innervate the supraspinatus and infraspinatus ${ }^{[22]}$. Through the X-ray in comparing the position of bilateral scapulae and glenohumeral joints in stroke patients, Culham et al. ${ }^{[23]}$ concluded the scapulae on the hemiplegic side were generally downward rotation, downward 
SS could be more easily. Anatomically, the downward rotation, downward displacement and outward displacement of the scapula may cause the higher tension of the suprascapular nerve, then lead to pull injury. However, the exact injury mechanism is still unclear.

Tsur et al. ${ }^{[9]}$ investigated the electrophysiological parameters of axillary nerve in patients with the SS after stroke and their parameters displayed that axillary nerve damage may occur. Chino et al. ${ }^{[5]}$ found that in stroke patients with the SS, the latency of the suprascapular, axillary, musculocutaneous and radial nerves on the HUE was longer than the reference values and the corresponding muscles had spontaneous potential. However, this study only investigated the latency, conduction velocity and spontaneous potential of the relevant motor nerves, and, it did not conduct the comparison between the healthy side and the HUE. Besides, CMAP and SNAP parameters were not considered by this study.

In post-stroke, the recovery of the HUE function should be related to the location/degree of injury and timing of rehabilitation intervention ${ }^{[24]}$. In addition, the results of the current study demonstrated that post-stroke patients with the occurrence of the SS may aggravate the damage of the HUE nerves which could impact the functional recovery of the HUE. Previous studies ${ }^{[25,26]}$ have suggested that long-term denervation can lead to muscular dystrophy and irreversible loss of neuromuscular junctions. Therefore, combining with the results of the current study, the authors speculate that if the prevention strategies of the SS are carried out in the early stage of stroke, it could reduce the degree of the HUE nerve damage. However, this speculation still needs further study to confirm.

Limitations of the current study: 1) although the grouping of all patients was matched according to the type of stroke, it was difficult to accurately control the damage degree of central nerve system in both groups; 2) in this study, because not all patients underwent shoulder radiography, no correlation study between the degree of shoulder subluxation/the change of scapular position and the degree of upper limb nerves damage was performed; 3 ) due to the insufficient samples of needle electromyography examination in both groups, there was no comparison of electromyographic signals of each muscle innervated by the upper limb peripheral nerves was made.

In conclusion, stroke may lead to extensive damage of the HUE nerves, and the SS may aggravate the damage degree of the HUE nerves, especially in the axillary, the musculocutaneous and the suprascapular nerves. The occurrence of the SS in post-stroke patients should impact the functional recovery of the HUE. Therefore, the protection of the shoulder joint on the HUE should be strengthened in the early stage of stroke. Follow-up studies can explore the change rule of the impact of SS on nerve conduction in hemiplegia, and the effectiveness of different shoulder protection strategies on nerve conduction and function in the HUE after stroke.

\section{Abbreviations}

\section{CMAP}


compound muscle action potential; HUE:hemiplegic upper extremity; N-SS:non-shoulder subluxation; SNAP:sensory nerve action potential; SS:shoulder subluxation.

\section{Declarations}

\section{Ethics approval and consent to participate}

Ethics approval was approved by the Medical Ethics Committee of the Affiliated Suzhou Science and Technology town Hospital of Nanjing Medical University.

\section{Consent for publication}

Qinfeng Wu confirms that he had full access to all the data in the study and had final responsibility for the decision to submit for publication. Consent for publication of identifying personal or clinical details of participants that compromise anonymity is not applicable.

\section{Availability of data and materials}

The datasets used and/or analyzed during the current study are available from the corresponding author upon reasonable request.

\section{Competing interests}

The author(s) declared no potential conflicts of interest with respect to the research, authorship, and/or publication of this article.

\section{Funding}

No funder supported the study.

\section{Authors' contributions}

XL1 and ZY were responsible for designing and performing the experiments, extracting and analyzing data, preparing the tables, interpreting the results, updating the reference lists, and wrote the drafts of the manuscript. SW, PX, TW, XZ, XL2, YZ, YL and NM performed the experiments, screened the potentially eligible studies, and extracted data. QW conceived the experimental design and reviewed the drafts of the manuscript. All authors read and approved the final manuscript.

\section{Acknowledgment}

We thank all the staff who kindly helped in facilitating the experiment.

\section{References}


[1] Arya K N, Pandian S, Puri V. Rehabilitation methods for reducing shoulder subluxation in post-stroke hemiparesis: a systematic review[J]. Top Stroke Rehabil,2018,25(1):68-81.

[2] Stolzenberg D, Siu G, Cruz E. Current and Future Interventions for Glenohumeral Subluxation in Hemiplegia Secondary to Stroke[J]. Top Stroke Rehabil,2012,19(5):444-456.

[3] Kumar P, Swinkels A. A critical review of shoulder subluxation and its association with other poststroke complications[J]. Phys Ther Rev,2009,14(1):13-25.

[4] Louise A, Elisabeth P, Birgitta L, et al. Profile of upper limb recovery and development of secondary impairments in patients after stroke with a disabled upper limb: An observational study[J]. Physiother Theory Pract,2020,36(1):196-202.

[5] Chino N. Electrophysiological investigation on shoulder subluxation in hemiplegics[J]. Scand J Rehabil Med,1981,13(1):17-21.

[6] İsnaç F, Aşkin A, Tosun A. Ultrasonographic and electrophysiologic evaluation of median and ulnar nerves in chronic stroke patients with upper extremity spasticity[J]. Somatosens Mot Res,2019,36(2):144-150.

[7] Picelli A, Tamburin S, Berto G, et al. Electrodiagnostic and nerve ultrasonographic features in upper limb spasticity: an observational study[J]. Funct Neurol,2017,32(3):119-122.

[8] Marco P, Benedetta V, Massimiliano $\mathrm{M}$, et al. Peripheral nerve conduction abnormalities in nonparetic side of ischemic stroke patients[J]. J Clin Neurophysiol,2010,27(27):48-51.

[9] Tsur A, Ring H. Axillary nerve conduction changes in hemiplegia[J]. J Brachial Plex Peripher Nerve $\operatorname{lnj}, 2008,3(1): 26$.

[10] Weyland C S, Neuberger U, Seker F, et al. Effect of Treatment Technique on Radiation Exposure in Mechanical Thrombectomy for Acute Ischaemic Stroke: A Matched-Pair Analysis[J]. Neuroradiol $\mathrm{J}, 2020$ (Online ahead of print).

[11] Petchkrua W, Weiss D J, Patel R R. Reassessment of the Incidence of Complex Regional Pain Syndrome Type 1 Following Stroke[J]. Neurorehabil Neural Repair,2000,14(1):59-63.

[12] Doughty C T, Bowley M P. Entrapment Neuropathies of the Upper Extremity[J]. Med Clin North Am,2019,103(2):357-370.

[13] Association, American, Diabetes. 2. Classification and Diagnosis of Diabetes: Standards of Medical Care in Diabetes-2019[J]. Diabetes Care,2019,42(Suppl 1):S13-S28.

[14] Preston D C, Shapiro B E. Electromyography and Neuromuscular Disorders: Clinical Elentronhwvinlnair CorrelatinnclMl 3rd ad I ondon:Elsevier Inc,2013. Loading [MathJax]/jax/output/CommonHTML/jax.js 
[15] Brunnstrom S, Sawner K A, Lavigne J M. Brunnstrom's movement therapy in hemiplegia: A Neurophysiological Approach[M]. 2 ed. Pennsylvania: JB Lippincott Company,1992.

[16] Spaans F, Wilts G. Denervation due to lesions of the central nervous system: An EMG study in cases of cerebral contusion and cerebrovascular accidents[J]. J Neurol Sci,1982,57(2):291-305.

[17] Chokroverty S, Medina J. Electrophysiological study of hemiplegia. Motor nerve conduction velocity, brachial plexus latency, and electromyography[J]. Arch Neurol,1978,35(6):360-363.

[18] Takebe K, Narayan M G, Kukulka C, et al. Slowing of nerve conduction velocity in hemiplegia: possible factors[J]. Arch Phys Med Rehabil,1975,56(7):285-289.

[19] Iruthayarajah J, Wiener J, Illiescu A, et al. Evidence-Based Review of Stroke Rehabilitation, Chap. 11:Hemiplegic Shoulder Pain \& Complex Regional Pain Syndrome[M]. 19th ed. Ontario:Canadian Partnership for Stroke Recovery,2019.

[20] Gutkowska O, Martynkiewicz J, Urban M, et al. Brachial plexus injury after shoulder dislocation: a literature review[J]. Neurosurg Rev,2018,2018(6):1-17.

[21] Shah R, Koris J, Wazir A, et al. Anterior Humeral Circumflex Artery Avulsion With Brachial Plexus Injury Following an Isolated Traumatic Anterior Shoulder Dislocation[J]. BMJ Case Rep,2016,2016:r2015213497.

[22] Kahle W, Frotscher M. Color Atlas of Human Anatomy, Vol. 3: Nervous System and Sensory Organs[M]. 7th ed. Stuttgart:Thieme Medical Publishers,2015.

[23] Culham E G, Noce R R, Bagg S D. Shoulder complex position and glenohumeral subluxation in hemiplegia[J]. Arch Phys Med Rehabil,1995,76(9):857-864.

[24] Raghavan P. Upper Limb Motor Impairment After Stroke[J]. Phys Med Rehabil Clin N Am,2015,26(4):599-610.

[25] Tuffaha S H, Budihardjo J D, Sarhane K A, et al. Growth Hormone Therapy Accelerates Axonal Regeneration, Promotes Motor Reinnervation, and Reduces Muscle Atrophy following Peripheral Nerve Injury[J]. Plast Reconstr Surg,2016,137(6):1771-1780.

[26] Ruven C, Li W, Li H, et al. Transplantation of Embryonic Spinal Cord Derived Cells Helps to Prevent Muscle Atrophy after Peripheral Nerve Injury[J]. Int J Mol Sci,2017,18(3):511.

Table legends

Table 1. Evaluation of upper limb motor nerve conduction

CMAP: compound muscle action potential

Loading [MathJax]/jax/output/CommonHTML/jax.js

Page 18/20 
Table 2. Evaluation of upper limb sensory nerve conduction

SNAP: sensory nerve action potential

Table 3. Clinical characteristics of patients with or without SS

SS: Shoulder subluxation; N-SS: Non-shoulder subluxation.

Table 4. The CMAP amplitude (mV) of peripheral nerves on upper limb in patients with or without SS

Values are mean \pm SD. CMAP: compound muscle action potential; SS: Shoulder subluxation; N-SS: Nonshoulder subluxation. Compared with N-SS group, $\varangle \mathrm{P} \llbracket 0.05 ; \varangle \mathrm{P} \llbracket 0.01$

Table 5. The CMAP latency (msecs) of peripheral nerves on upper limb in patients with or without SS

Values are mean \pm SD. CMAP: compound muscle action potential; SS: Shoulder subluxation; N-SS: Nonshoulder subluxation. Compared with N-SS group, $₫ \mathrm{P} \otimes 0.01 ; \varangle \mathrm{P} \otimes 0.00$

Table 6. The motor conduction velocity $(\mathrm{m} / \mathrm{sec})$ of peripheral nerves on upper limb in patients with or without SS

Values are mean \pm SD. SS: Shoulder subluxation; N-SS: Non-shoulder subluxation. Compared with N-SS group, $₫ \mathrm{P} \otimes 0.05$

Table 7. The SNAP amplitude $(\mu \mathrm{V})$ of peripheral nerves on upper limb in patients with or without SS Values are mean \pm SD. SNAP: sensory nerve action potential; SS: Shoulder subluxation; N-SS: Nonshoulder subluxation.

Table 8. The sensory conduction velocity $(\mathrm{m} / \mathrm{sec})$ of peripheral nerves on upper limb in patients with or without SS

Values are mean \pm SD. SS: Shoulder subluxation; N-SS: Non-shoulder subluxation.

Table 9. The Brunnstrom stage on affected upper limb of patients with or without SS

SS: Shoulder subluxation; N-SS: Non-shoulder subluxation.

Table 10. The Brunnstrom stage on affected hand of patients with or without SS

SS: Shoulder subluxation; N-SS: Non-shoulder subluxation.

\section{Figures}




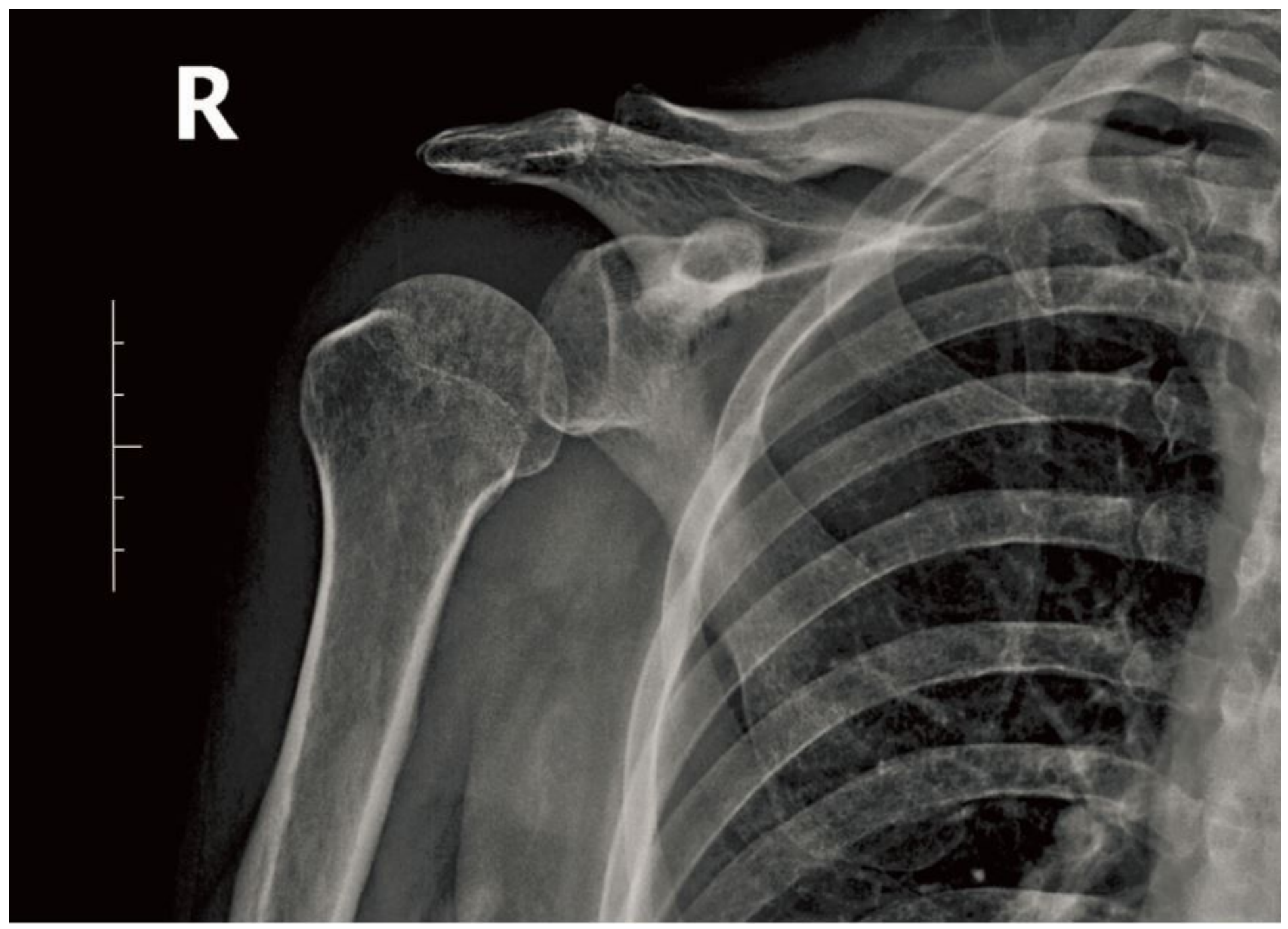

\section{Figure 1}

Shoulder subluxation, one or more fingers breadths in the upper part of the gleno-humeral joint space of the paralyzed shoulder, humeral head partially detached from glenoid. 